\title{
Genome sequence of Ensifer medicae strain WSM1115; an acid-tolerant Medicago-nodulating microsymbiont from Samothraki, Greece
}

\author{
Wayne Reeve $^{1 *}$, Ross Ballard ${ }^{2}$, John Howieson ${ }^{1}$, Elizabeth Drew ${ }^{2}$, Rui Tian ${ }^{1}$, Lambert Bräu ${ }^{3}$, \\ Christine Munk ${ }^{4}$, Karen Davenport ${ }^{4}$, Patrick Chain ${ }^{4}$, Lynne Goodwin ${ }^{4}$, loanna Pagani ${ }^{5}$, \\ Marcel Huntemann ${ }^{5}$, Konstantinos Mavrommatis ${ }^{6}$, Amrita Pati ${ }^{5}$, Victor Markowitz ${ }^{6}$, Natalia \\ Ivanova $^{5}$, Tanja Woyke ${ }^{5}$ \& Nikos Kyrpides ${ }^{5}$. \\ ${ }^{1}$ Centre for Rhizobium Studies, Murdoch University, Western Australia, Australia \\ ${ }^{2}$ South Australian Research and Development Institute, Urrbrae, South Australia, Australia \\ ${ }^{3}$ School of Life and Environmental Sciences, Deakin University, Victoria, Australia \\ ${ }^{4}$ Los Alamos National Laboratory, Bioscience Division, Los Alamos, New Mexico, USA \\ ${ }^{5}$ DOE Joint Genome Institute, Walnut Creek, California, USA \\ ${ }^{6}$ Biological Data Management and Technology Center, Lawrence Berkeley National \\ Laboratory, Berkeley, California, USA \\ *Correspondence: Wayne Reeve (W.Reeve@murdoch.edu.au)
}

Keywords: root-nodule bacteria, nitrogen fixation, rhizobia, Alphaproteobacteria

Ensifer medicae strain WSM1115 foms effective nitrogen fixing symbioses with a range of annual Medicago species and is used in commercial inoculants in Australia. WSM1115 is an aerobic, motile, Gram-negative, non-spore-forming rod. It was isolated from a nodule recovered from the root of burr medic (Medicago polymorpha) collected on the Greek Island of Samothraki. WSM1115 has a broad host range for nodulation and $\mathrm{N}$ fixation capacity within the genus Medicago, although this does not extend to all medic species. WSM1115 is considered saprophytically competent in moderately acid soils ( $\mathrm{pH}(\mathrm{CaCl}) 5.0)$, but it has failed to persist at field sites where soil salinity exceeded 10 $\mathrm{ECe}(\mathrm{dS} / \mathrm{m})$. Here we describe the features of $E$. medicae strain WSM1115, together with genome sequence information and its annotation. The $6,861,065 \mathrm{bp}$ high-quality-draft genome is arranged into 7 scaffolds of 28 contigs, contains 6,789 protein-coding genes and 83 RNA-only encoding genes, and is one of 100 rhizobial genomes sequenced as part of the DOE Joint Genome Institute 2010 Genomic Encyclopedia for Bacteria and Archaea-Root Nodule Bacteria (GEBA-RNB) project.

\section{Introduction}

The genus Medicago comprises 87 species of annual and perennial legumes, including some that were formerly recognized as Trigonella and Melilotus species [1]. A small number of annual Medicago species that have been domesticated are grown extensively in the sheep-wheat zone of southern Australia, particularly where pasture regeneration after a cropping phase is desirable. Annual Medicago species are grown on more than $20 \mathrm{M}$ ha [2] and are particularly valued for their contribution to farming systems, in which Medicago fix around $25 \mathrm{~kg}$ of $\mathrm{N}$ per tonne of legume dry matter produced [3].

Medicago are nodulated by two species of root nodule bacteria (Ensifer medicae and Ensifer meliloti) that are recognized as being distinct based on their different nodulation and $\mathrm{N}_{2}$ fixation phenotypes in host interaction studies and more detailed analyses of their genetics $[4,5]$.

Ensifer medicae strain WSM1115 is used in Australia to produce commercial peat cultures (referred to as Group AM inoculants) for the inoculation of several species of annual Medicago (predominantly $M$. truncatula, $M$. polymorpha, $M$. scutellata, $M$. sphaerocarpus, M. murex, M. rugosa and M. orbicularis). WSM1115 has been used commercially since 2002 [6], when it replaced strain WSM688. WSM1115 was isolated from a nodule from the roots of burr medic (Medicago polymorpha) collected by Prof. John Howieson (Murdoch University, Australia) on the island of Samothraki, Greece.

WSM1115 was selected for use in commercial inoculants having demonstrated good $\mathrm{N}_{2}$-fixation capacity with the relevant medic hosts and adequate 
saprophytic competence in moderately acidic soil $\left(\mathrm{pH}\left(\mathrm{CaCl}_{2}\right)\right.$ 5).

Saprophytic competence in acidic soils is a requirement of strains used to inoculate Medicago because several species (M. murex, $M$. sphaerocarpus and M. polymorpha) are recommended and sown into soils below $\mathrm{pH}\left(\mathrm{CaCl}_{2}\right) 5.5$, a level that is known to limit both survival of medic rhizobia and nodulation processes [7-10]. Useful variation in saprophytic competence occurs between strains of medic rhizobia [9] and valuable insights into the mechanisms that confer acidity tolerance have been provided by studies using strain WSM419 [11], which has been recently sequenced [12]. However, the complex nature of soil adaptation means that in-situ field studies still provide the most reliable means of selecting an inoculant strain and were used to select WSM1115 for commercial use. In a cross row experiment comparing 15 strains on acidic sand $\left(\mathrm{pH}\left(\mathrm{CaCl}_{2}\right)\right.$ 5.0; Dowerin, West Australia), the nodulation of plants inoculated with WSM1115 was equal to or better than that of the other strains. This translated to better plant shoot weights, which were similar to those of plants inoculated with WSM688 (the incumbent inoculant strain at time of testing) and $48 \%$ greater when compared to former inoculant strain CC169 (J. G. Howieson unpublished data).

The nitrogen fixation capacity (effectiveness) of Medicago symbioses is characterized by strong interactions between the strain of rhizobia and species of Medicago [13-16]. Hence, the ability to form effective symbiosis with the species recommended for inoculation is an important consideration in inoculant strain selection. WSM1115 satisfies this requirement. In greenhouse tests it formed effective symbiosis with 16 genotypes of Medicago and overall produced $48 \%$ more shoot dry matter compared to plants inoculated with WSM688, the strain that it replaced (R.A. Ballard and N. Charman, unpublished data).

A limitation of strain WSM1115 is its poor persistence in moderately saline soils (e.g. where summer salinity levels exceed 10 ECe $(\mathrm{dS} / \mathrm{m}))$. Poor nodulation of regenerating pasture was first noted in 2004 during the field evaluation and domestication of the salt tolerant annual pasture legume messina (Melilotus siculus syn. Melilotus messanensis). Subsequent studies [17] confirmed that although WSM1115 was able to nodulate and form effective symbiosis with messina, it did not persist as well as other strains (e.g. SRDI554) through the summer months when salinity levels increased.

Here we present a preliminary description of the general features of Ensifer medicae strain WSM1115 together with its genome sequence and annotation.

\section{Classification and features}

Ensifer medicae strain WSM1115 is a motile, nonsporulating, non-encapsulated, Gram-negative rod in the order Rhizobiales of the class Alphaproteobacteria. The rod-shaped form varies in size with dimensions of approximately $0.5 \mu \mathrm{m}$ in width and $1.0 \mu \mathrm{m}$ in length (Figure 1A). It is fast growing, forming colonies within 3-4 days when grown on TY [18] or half strength Lupin Agar $(1 / 2 \mathrm{LA})$ [19] at $28^{\circ} \mathrm{C}$. Colonies on $1 / 2 \mathrm{LA}$ are opaque, slightly domed and moderately mucoid with smooth margins (Figure 1B).
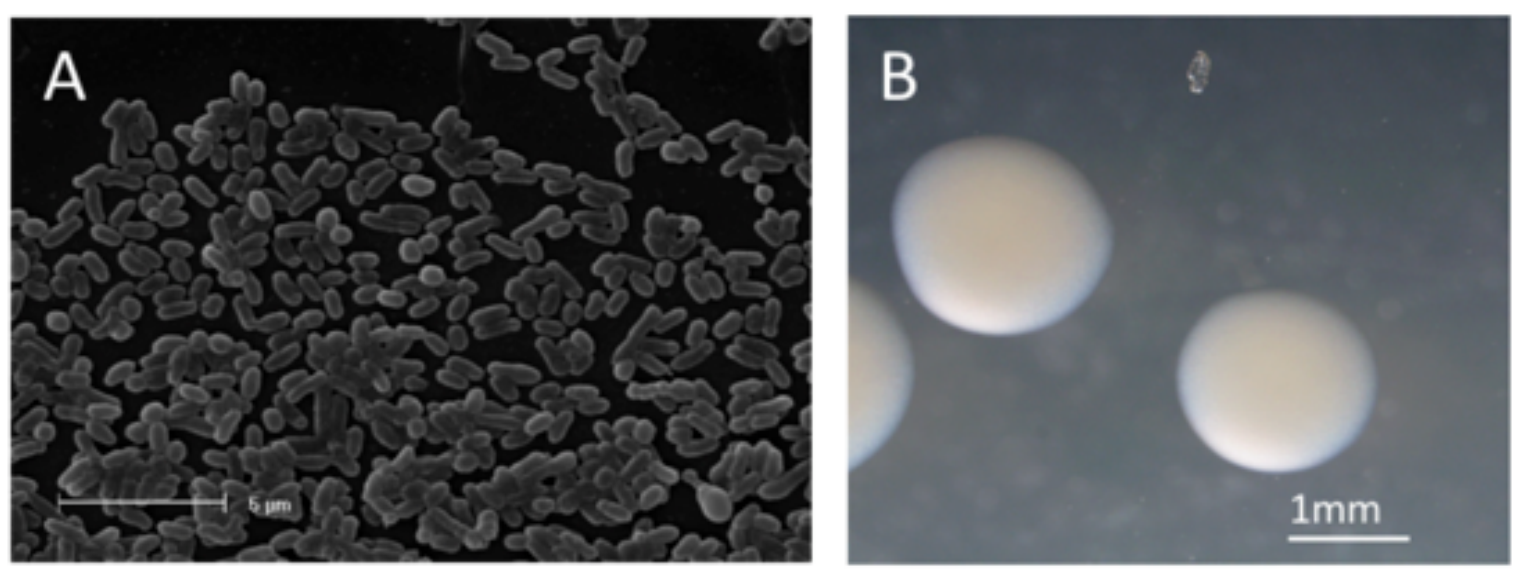

Figure 1. Images of Ensifer medicae strain WSM1115 using (A) scanning electron microscopy and (B) light microscopy to show the colony morphology on a solid medium. 
Minimum Information about the Genome Sequence (MIGS) is provided in Table 1 . Figure 2 shows the phylogenetic neighborhood of Ensifer medicae strain WSM1115 in a $16 \mathrm{~S}$ rRNA gene sequence based tree. This strain has $100 \%$ sequence identity $(1,366 / 1,366 \mathrm{bp})$ at the $16 \mathrm{~S}$ rRNA sequence level to the fully sequenced Ensifer medicae strain WSM419 [12] and 99\% 16S rRNA sequence (1362/1366 bp) identity to the fully sequenced E. meliloti Sm1021 [36].

Table 1. Classification and general features of Ensifer medicae strain WSM1115 according to the MIGS recommendations [20]

\begin{tabular}{|c|c|c|c|}
\hline MIGS ID & Property & Term & Evidence code \\
\hline & \multirow{8}{*}{ Current classification } & Domain Bacteria & TAS [21] \\
\hline & & Phylum Proteobacteria & TAS [22] \\
\hline & & Class Alphaproteobacteria & TAS [23,24] \\
\hline & & Order Rhizobiales & TAS $[22,25]$ \\
\hline & & Family Rhizobiaceae & TAS $[26,27]$ \\
\hline & & Genus Ensifer & TAS [28-30] \\
\hline & & Species Ensifer medicae & TAS [29] \\
\hline & & Strain WSM1115 & \\
\hline & Gram stain & Negative & IDA \\
\hline & Cell shape & Rod & IDA \\
\hline & Motility & Motile & IDA \\
\hline & Sporulation & Non-sporulating & NAS \\
\hline & Temperature range & Mesophile & NAS \\
\hline & Optimum temperature & $28^{\circ} \mathrm{C}$ & NAS \\
\hline & Salinity & Non-halophile & NAS \\
\hline \multirow[t]{3}{*}{ MIGS-22 } & Oxyg en requirement & Aerobic & IDA \\
\hline & Carbon source & Varied & NAS \\
\hline & Energy source & Chemoorg anotroph & NAS \\
\hline MIGS-6 & Habitat & Soil, root nodule, on host & IDA \\
\hline MIGS-15 & Biotic relationship & Free living, symbiotic & IDA \\
\hline \multirow[t]{3}{*}{ MIGS-14 } & Pathog enicity & Non-pathogenic & IDA \\
\hline & Biosafety level & 1 & TAS [31] \\
\hline & Isolation & Root nodule & IDA \\
\hline MIGS-4 & Geographic location & Samothraki, Greece & IDA \\
\hline MIGS-5 & Time of sample collection & May, 1987 & IDA \\
\hline MIGS-4.1 & Latitude & 40.4900 & IDA \\
\hline MIGS-4.2 & Long itude & 25.6500 & IDA \\
\hline MIGS-4. 3 & Depth & $<10 \mathrm{~cm}$ & IDA \\
\hline MIGS-4.4 & Altitude & $325 \mathrm{~m}$ & IDA \\
\hline
\end{tabular}

Evidence codes - IDA: Inferred from Direct Assay; TAS: Traceable Author Statement (i.e., a direct report exists in the literature); NAS: Non-traceable Author Statement (i.e., not directly observed for the living, isolated sample, but based on a generally accepted property for the species, or anecdotal evidence). These evidence codes are from the Gene Ontology project [32]. 


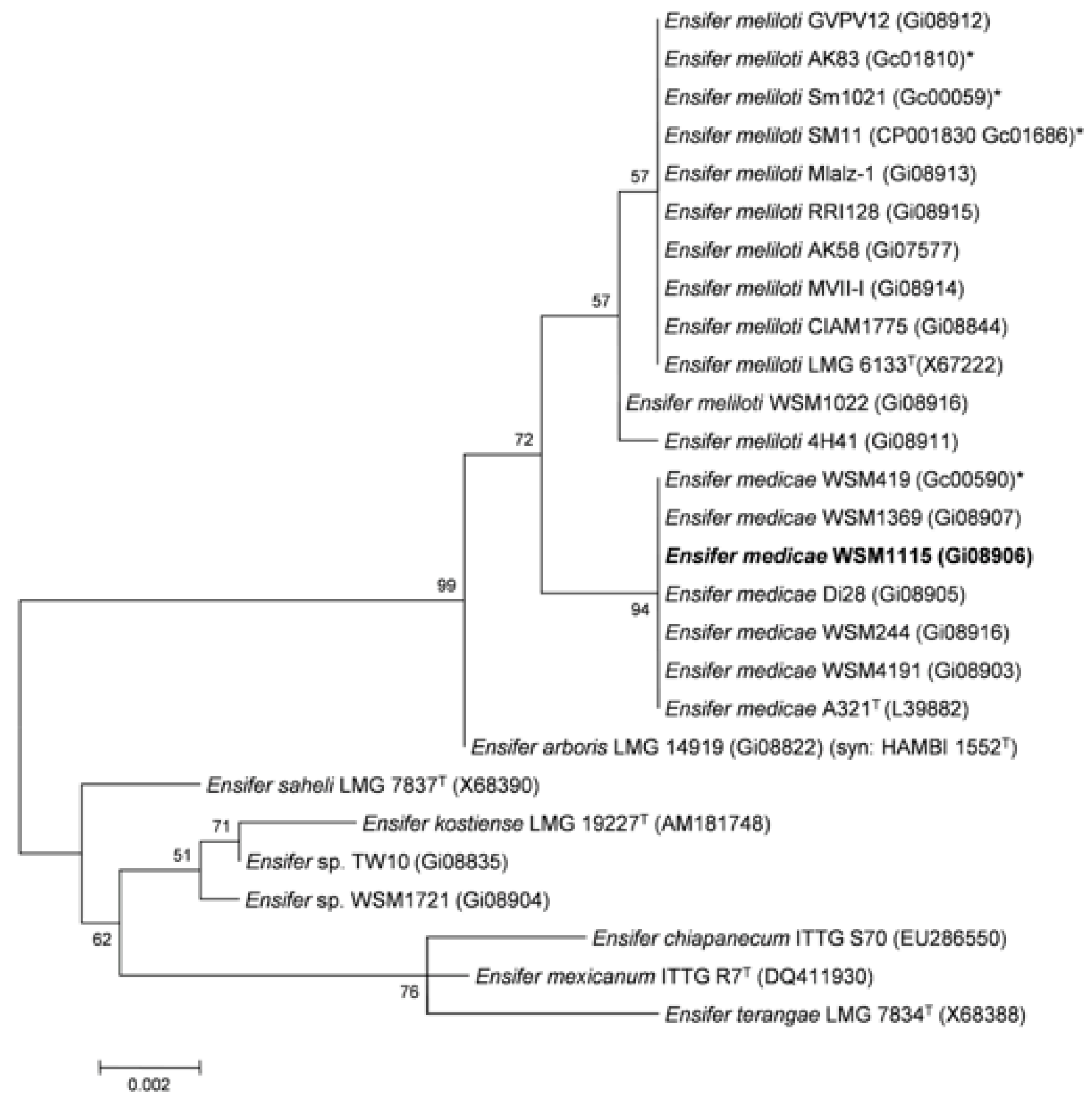

Figure 2. Phylogenetic tree showing the relationship of Ensifer medicae WSM1115 (shown in bold print) to other Ensifer spp. in the order Rhizobiales based on alig ned sequences of the 16S rRNA gene (1,290 bp internal region). All sites were informative and there were no gap-containing sites. Phylogenetic analyses were performed using MEGA, version 5 [33]. The tree was built using the Maximum-Likelihood method with the General Time Reversible model [34]. Bootstrap analysis [35] with 500 replicates was performed to assess the support of the clusters. Type strains are indicated with a superscript T. Brackets after the strain name contain a DNA database accession number and/or a GOLD ID (beginning with the prefix G) for a sequencing project registered in GOLD [32 ]. Published genomes are indicated with an asterisk. 
Table 2. Compatibility of Ensifer medicae WSM1115 with various Medicago and allied genera for nodulation (Nod) and $\mathrm{N}_{2}$-fixation (Fix)

\begin{tabular}{|c|c|c|c|c|c|c|}
\hline Species Name & Cultivar or line & Common Name & Growth Type & Nod & Fix & Reference \\
\hline M. polymorpha & Santiago/Cavalier/Scimitar & Burr & Annual & + & + & IDA \\
\hline M. truncatula. & Caliph/Jester & Barrel & Annual & + & + & IDA \\
\hline M. murex & Zodiac & Murex & Annual & + & + & IDA \\
\hline M. sphaerocarpus & Orion & Sphere & Annual & + & + & IDA \\
\hline M. scutellata & Sava/Silver/Essex & Snail & Annual & + & + & IDA \\
\hline M. rugosa & Paraponto & Gama & Annual & + & + & IDA \\
\hline M. littoralis & Herald/Harbinger & Strand & Annual & + & Poor & IDA \\
\hline M. orbicularis & Estes & Button & Annual & + & + & [15] \\
\hline M. rigiduloides & Accession PI 227850 & Rigid & Annual & $+(\mathrm{w})$ & - & [15] \\
\hline M. rigidula & Accession PI 495552 & Tifton & Annual & $+(\mathrm{w})$ & - & [15] \\
\hline M. arabica & Local ecotype & Spotted & Annual & + & + & [15] \\
\hline M. minima & Devine & Woolly burr & Annual & + & + & [15] \\
\hline M. sativa & SARDI Ten & Lucerne & Perennial & + & + & IDA \\
\hline M. Iupulina & 'BEBLK' & Black & Perennial & + & + & [15] \\
\hline Melilotus siculus & Accessions SA40006 \& 39909 & Messina & Annual & + & + & [17] \\
\hline Melilotus albus & various accessions & Bokhara clover & Biennial & + & + & IDA \\
\hline
\end{tabular}

(w) indicates nodules present were white.

IDA: Inferred from Direct Assay from the Gene Ontology project [37].

\section{Symbiotaxonomy}

Ensifer medicae strain WSM1115 forms nodules (Nod+) and fixes $\mathrm{N}_{2}(\mathrm{Fix}+)$ with a range of annual and perennial Medicago species and Melilotus species (Table 2). Levels of $\mathrm{N}_{2}$ fixation in combination with Medicago littoralis is suboptimal, that species generally forming more effective associations with strains of Ensifer meliloti including strain RRI128 [38]. The level of $\mathrm{N}_{2}$ fixation with Melilotus albus is also noted as positive, but has been observed to vary markedly with different plant accessions.

\section{Genome sequencing and annotation information \\ Genome project history}

This organism was selected for sequencing on the basis of its environmental and agricultural relevance to issues in global carbon cycling, alternative energy production, and biogeochemical importance, and is part of the Community Sequencing Program at the U.S. Department of Energy, Joint Genome Institute (JGI) for projects of relevance to agency missions. The genome project is deposited in the Genomes OnLine Database [32] and a high-quality-draft genome sequence in IMG/GEBA. Sequencing, finishing and annotation were performed by the JGI. A summary of the project information is shown in Table 3. 
Table 3. Genome sequencing project information for Ensifer medicae strain WSM1115

\begin{tabular}{lll}
\hline MIGS ID & Property & Term \\
\hline MIGS-31 & Finishing quality & Permanent high quality draft \\
MIGS-28 & Libraries used & $2 \times$ Illumina libraries; Std short PE \& CLIP long PE \\
MIGS-29 & Sequencing platforms & Illumina HiSeq 2000 \\
MIGS-31.2 & Sequencing coverage & $530 \times$ Illumina \\
MIGS-32 & Assemblers & with Allpaths, version 38445, Velvet 1.1.05, phrap 4.24 \\
& Gene calling methods & Prodigal 1.4, GenePRIMP \\
& Genbank ID & AQZC01000000 \\
& GOLD ID & April 22, 2013 \\
& NCBI project ID & Gi08906 \\
& Database: IMG-GEBA & 2512875026 \\
& Project relevance & Symbiotic $\mathrm{N}_{2}$ fixation, ag riculture \\
\hline
\end{tabular}

\section{Growth conditions and DNA isolation}

Ensifer medicae strain WSM1115 was cultured to mid logarithmic phase in $60 \mathrm{ml}$ of TY rich medium on a gyratory shaker at $28^{\circ} \mathrm{C}$ [39]. DNA was isolated from the cells using a CTAB (Cetyl trimethyl ammonium bromide) bacterial genomic DNA isolation method [40].

\section{Genome sequencing and assembly}

The genome of Ensifer medicae strain WSM1115 was sequenced at the Joint Genome Institute (JGI) using Illumina [41] data. An Illumina standard paired-end library with a minimum insert size of $270 \mathrm{bp}$ was used to generate $23,080,558$ reads totaling 3,462 Mbp and an Illumina CLIP pairedend library with an average insert size of 9,584 + 2,493 bp was used to generate 2,163,668 reads totaling $324 \mathrm{Mbp}$ of Illumina data (unpublished, Feng Chen).

All general aspects of library construction and sequencing performed at the JGI can be found at the JGI user home [40]. The initial draft assembly contained 57 contigs in 11 scaffolds. The initial draft data was assembled with Allpaths, version 38445 , and the consensus was computationally shredded into $10 \mathrm{Kbp}$ overlapping fake reads (shreds). The Illumina draft data was also assembled with Velvet, version 1.1.05 [42], and the consensus sequences were computationally shredded into $1.5 \mathrm{Kbp}$ overlapping fake reads (shreds). The Illumina draft data was assembled again with Velvet using the shreds from the first Velvet assembly to guide the next assembly. The consensus from the second VELVET assembly was shredded into $1.5 \mathrm{Kbp}$ overlapping fake reads. The fake reads from the Allpaths assembly and both Velvet assemblies and a subset of the Illumina CLIP paired-end reads were assembled using parallel phrap, version 4.24 (High Performance Software, LLC). Possible mis-assemblies were corrected with manual editing in Consed [43-45]. Gap closure was accomplished using repeat resolution software (Wei Gu, unpublished), and sequencing of bridging PCR fragments. The estimated total size of the genome is $6.9 \mathrm{Mbp}$ and the final assembly is based on 3,654 Mbp of Illumina draft data, which provides an average $530 \times$ coverage of the genome.

\section{Genome annotation}

Genes were identified using Prodigal [46] as part of the Oak Ridge National Laboratory genome annotation pipeline, followed by a round of manual curation using the JGI GenePRIMP pipeline [47]. The predicted CDSs were translated and used to search the National Center for Biotechnology Information (NCBI) nonredundant database, UniProt, TIGRFam, Pfam, PRIAM, KEGG, COG, and InterPro databases. These data sources were combined to assert a product description for each 
predicted protein. Non-coding genes and miscellaneous features were predicted using tRNAscanSE [48], RNAMMer [49], Rfam [50], TMHMM [51], and SignalP [52]. Additional gene prediction analyses and functional annotation were performed within the Integrated Microbial Genomes (IMGER) platform [53].

\section{Genome properties}

The genome is 6,861,065 nucleotides with $61.16 \%$ GC content (Table 4) and comprised of 7 scaffolds (Figures 3a,3b,3c,3d,3e,3f and Figure 3g) From a total of 6,872 genes, 6,789 were protein encoding and 83 RNA only encoding genes. The majority of genes (76.25\%) were assigned a putative function whilst the remaining genes were annotated as hypothetical. The distribution of genes into COGs functional categories is presented in Table 5.

Table 4. Genome Statistics for Ensifer medicae strain WSM1115

\begin{tabular}{|c|c|c|}
\hline Attribute & Value & $\%$ of Total \\
\hline Genome size (bp) & $6,861,065$ & 100.00 \\
\hline DNA coding region (bp) & $5,918,651$ & 86.26 \\
\hline DNA G+C content (bp) & $4,196,062$ & 61.16 \\
\hline Number of scaffolds & 7 & \\
\hline Number of contigs & 28 & \\
\hline Total gene & 6,872 & 100.00 \\
\hline RNA genes & 83 & 1.21 \\
\hline rRNA operons & 3 & 0.04 \\
\hline Protein-coding genes & 6,789 & 98.79 \\
\hline Genes with function prediction & 5,240 & 76.25 \\
\hline Genes assigned to COGs & 5,168 & 75.20 \\
\hline Genes assig ned Pfam domains & 5,424 & 78.93 \\
\hline Genes with signal peptides & 571 & 8.31 \\
\hline Genes coding membrane proteins & 1,483 & 21.58 \\
\hline CRISPR repeats & 0 & \\
\hline
\end{tabular}



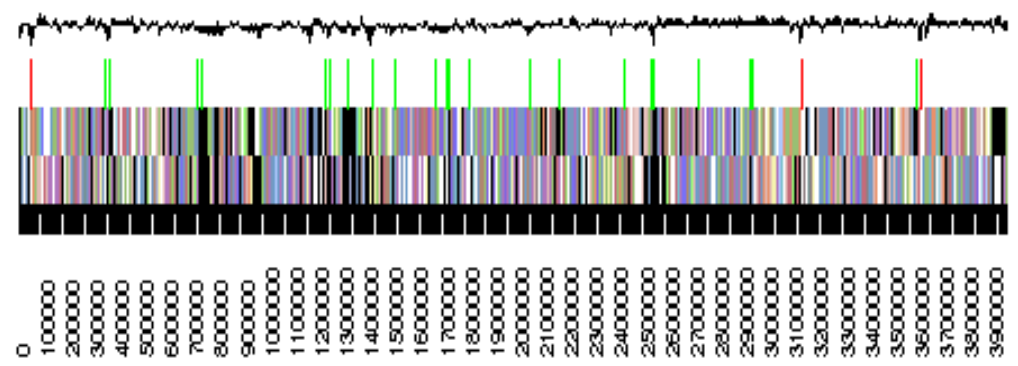

Figure 3a. Graphical maps of SinmedDRAFT_Scaffold1.2 of the Ensifer medicae strain WSM1115 genome sequence. From bottom to the top of each scaffold: Genes on forward strand (color by COG categories as denoted by the IMG platform), Genes on reverse strand (color by COG categories), RNA genes (tRNAs green, sRNAs red, other RNAs black), GC content, GC skew.

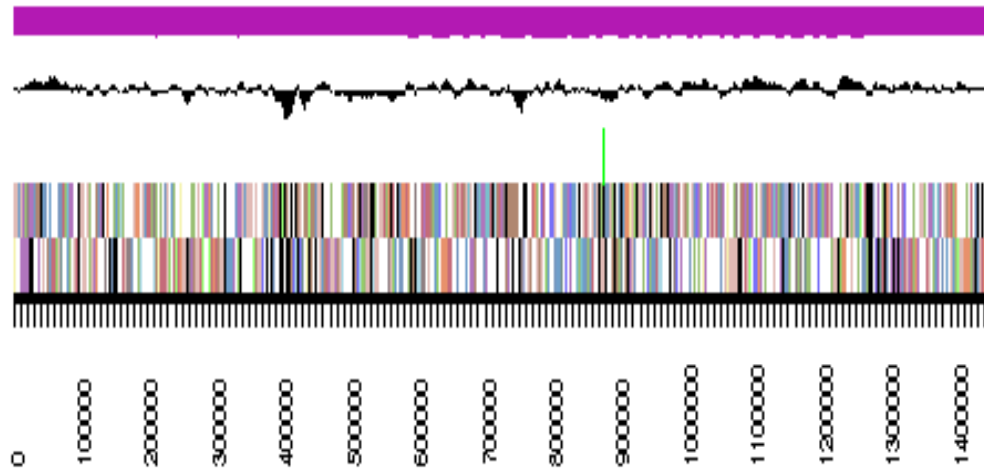

Figure 3b. Graphical maps of SinmedDRAFT_Scaffold2.1 of the Ensifer medicae strain WSM1115 genome sequence. From bottom to the top of each scaffold: Genes on forward strand (color by COG categories as denoted by the IMG platform), Genes on reverse strand (color by COG categories), RNA genes (tRNAs green, sRNAs red, other RNAs black), GC content, GC skew.

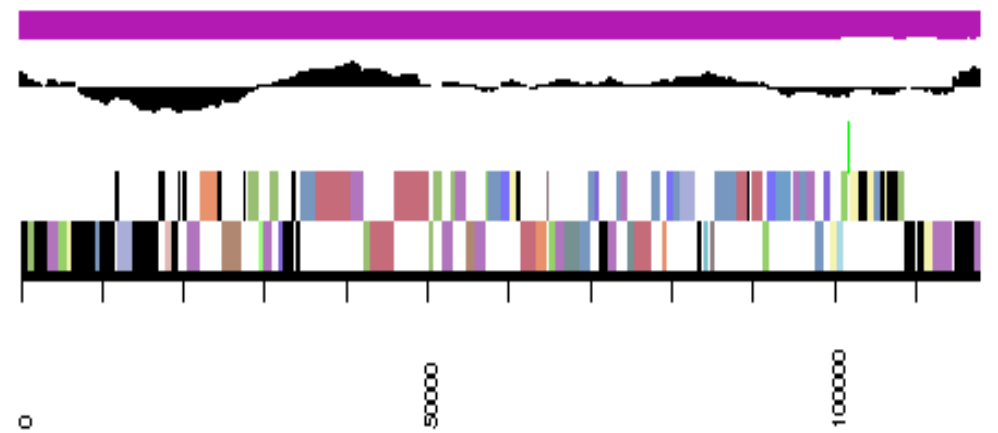

Figure 3c. Graphical maps of SinmedDRAFT_Scaffold5.3 of the Ensifer medicae strain WSM1115 genome sequence. From bottom to the top of each scaffold: Genes on forward strand (color by COG categories as denoted by the IMG platform), Genes on reverse strand (color by COG categories), RNA genes (tRNAs green, sRNAs red, other RNAs black), GC content, GC skew. 


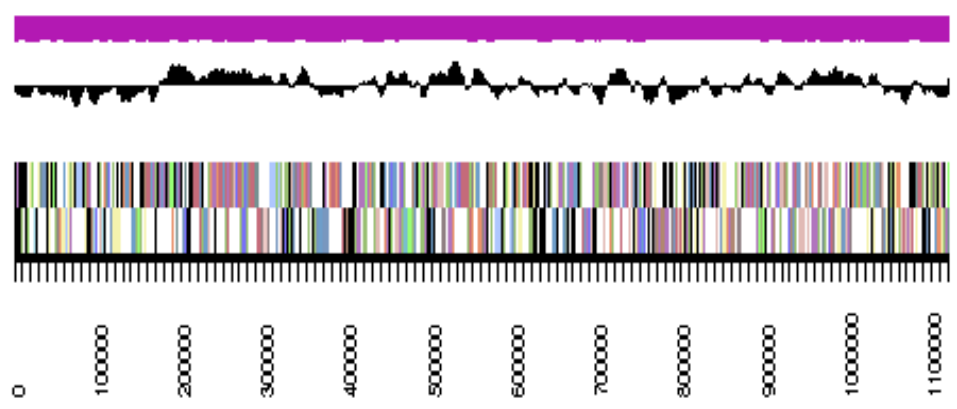

Figure 3d. Graphical maps of SinmedDRAFT_Scaffold3.7 of the Ensifer medicae strain WSM1115 genome sequence. From bottom to the top of each scaffold: Genes on forward strand (color by COG categories as denoted by the IMG platform), Genes on reverse strand (color by COG categories), RNA genes (tRNAs green, sRNAs red, other RNAs black), GC content, GC skew.

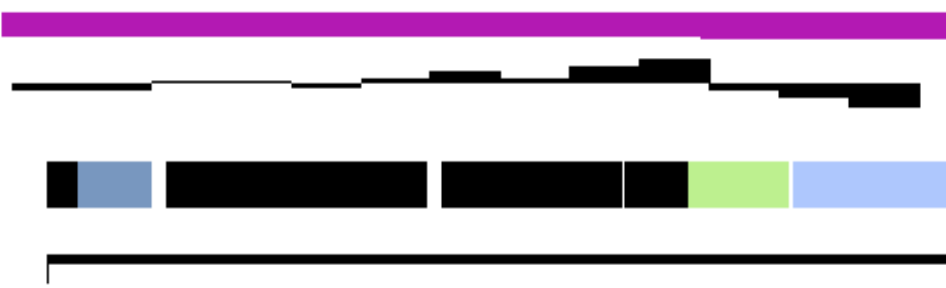

Figure 3e. Graphical maps of SinmedDRAFT_Scaffold6.5 of the Ensifer medicae strain WSM1115 genome sequence. From bottom to the top of each scaffold: Genes on forward strand (color by COG categories as denoted by the IMG platform), Genes on reverse strand (color by COG categories), RNA genes (tRNAs g reen, sRNAs red, other RNAs black), GC content, GC skew.
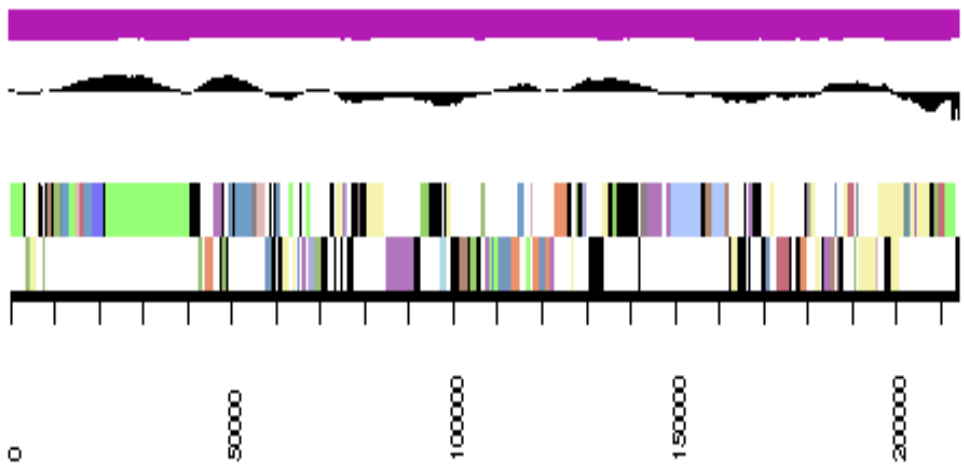

Figure 3f. Graphical maps of SinmedDRAFT_Scaffold4.6 of the Ensifer medicae strain WSM1115 genome sequence. From bottom to the top of each scaffold: Genes on forward strand (color by COG categories as denoted by the IMG platform), Genes on reverse strand (color by COG categories), RNA genes (tRNAs green, sRNAs red, other RNAs black), GC content, GC skew. 


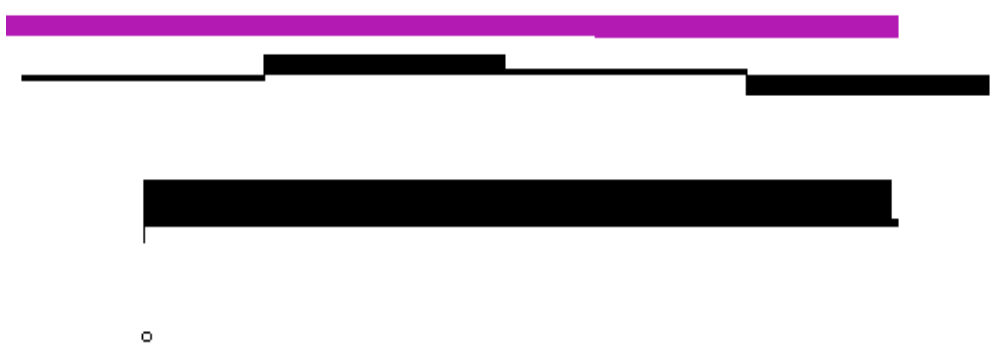

Figure 3g. Graphical maps of SinmedDRAFT_Scaffold7.4 of the Ensifer medicae strain WSM1115 genome sequence. From bottom to the top of each scaffold: Genes on forward strand (color by COG categories as denoted by the IMG platform), Genes on reverse strand (color by COG categories), RNA genes (tRNAs green, sRNAs red, other RNAs black), GC content, GC skew.

Table 5. Number of protein coding genes of Ensifer medicae strain WSM1115 associated with the general COG functional categ ories.

\begin{tabular}{crrl}
\hline Code & Value & \%age & COG Categ ory \\
\hline J & 186 & 3.23 & Translation, ribosomal structure and biogenesis \\
A & 0 & 0.00 & RNA processing and modification \\
K & 527 & 9.16 & Transcription \\
L & 269 & 4.68 & Replication, recombination and repair \\
B & 3 & 0.05 & Chromatin structure and dynamics \\
D & 43 & 0.75 & Cell cycle control, mitosis and meiosis \\
Y & 0 & 0.00 & Nuclear structure \\
V & 55 & 0.96 & Defense mechanisms \\
T & 244 & 4.24 & Signal transduction mechanisms \\
M & 272 & 4.73 & Cell wall/membrane biog enesis \\
N & 68 & 1.18 & Cell motility \\
Z & 0 & 0.00 & Cytoskeleton \\
W & 1 & 0.02 & Extracellular structures \\
U & 112 & 1.95 & Intracellular trafficking and secretion \\
O & 195 & 3.39 & Posttranslational modification, protein turnover, chaperones \\
C & 335 & 5.82 & Energy production conversion \\
G & 575 & 10.00 & Carbohydrate transport and metabolism \\
E & 609 & 10.59 & Amino acid transport metabolism \\
F & 106 & 1.84 & Nucleotide transport and metabolism \\
H & 194 & 3.37 & Coenzyme transport and metabolism \\
I & 205 & 3.56 & Lipid transport and metabolism \\
P & 286 & 4.97 & Inorganic ion transport and metabolism \\
Q & 164 & 2.85 & Secondary metabolite biosynthesis, transport and catabolism \\
R & 726 & 12.62 & General function prediction only \\
S & 577 & 10.03 & Function unknown \\
- & 1,704 & 24.80 & Not in COGs \\
- & 5,752 & & Total \\
\hline & & & \\
& &
\end{tabular}




\section{Acknowledgements}

This work was performed under the auspices of the US Department of Energy's Office of Science, Biological and Environmental Research Program, and by the University of California, Lawrence Berkeley National Laboratory under contract No. DE-AC02-05CH11231, Lawrence Livermore National Laboratory under Contract No. DEAC52-07NA27344, and Los Alamos National Laboratory under contract No. DE-AC02-06NA25396. We grate-

\section{References}

1. Small E. Alfalfa and Relatives: Evolution and Classification of Medicago. Ottawa, Canada: NRC

Reserach Press; 2011.

2. Hill MJ, Donald GE. Australian Temperate Pastures Database National Pastures Improvement Coordinating Committee; 1998.

3. Peoples MB, Baldock JA. Nitrog en dynamics of pastures: nitrog en fixation inputs, the impact of legumes on soil nitrogen fertility, and the contributions of fixed nitrogen to Australian farming systems. Aust J Exp Agric 2001; 41:327-346. http://dx.doi.org/10.1071/EA99139

4. Rome S, Brunel B, Normand P, Fernandez M, Cleyet-Marel JC. Evidence that two genomic species of Rhizobium are associated with Medicago truncatula. Arch Microbiol 1996; 165:285-288. PubMed

http://dx.doi.org/10.1007/s002030050328

5. Rome S, Fernandez MP, Brunel B, Normand P, Cleyet-Marel JC. Sinorhizobium medicae sp. nov., isolated from annual Medicago spp. Int I Syst Bacteriol 1996; 46:972-980. PubMed http://dx.doi.org/10.1099/00207713-46-4-972

6. Bullard GK, Roughley RJ, Pulsford DJ. The legume inoculant industry and inoculant quality control in Australia: 1953-2003. Aust J Exp Agric 2005; 45:12 7-140. http://dx.doi.org/10.1071/EA03159

7. Brockwell J, Pilka A, Holliday RA. Soil pH is a major determinant of the numbers of naturally occurring Rhizobium meliloti in non-cultivated soils in central New South Wales. Aust J Exp Agric 1991; 31:211-219. http://dx.doi.org/10.1071/EA9910211

8. Denton MD, Hill CR, Bellotti WD, Coventry DR. Nodulation of Medicago truncatula and Medicago polymorpha in two pastures of contrasting soil $\mathrm{pH}$ and rhizobial populations. App/ Soil Ecol 2007; 35:441-448. http://dx.doi.org/10.1016/j.apsoil.2006.08.001

9. Howieson JG, Ewing MA. Acid tolerance in the Rhizobium meliloti-Medicago symbiosis. Aust J fully acknowledge the funding received from the Murdoch University Strategic Research Fund through the Crop and Plant Research Institute (CaPRI) and the Centre for Rhizobium Studies (CRS) at Murdoch University and the GRDC National Rhizobium Program (Project UMU63).

Agric Res 1986; 37:55-64. http://dx.doi.org/10.1071/AR9860055

10. Howieson JG, Robson AD, Abbott LK. Acidtolerant species of Medicago produce root exudates at low $\mathrm{pH}$ which induce the expression of nodulation genes in Rhizobium meliloti. Aust $J$ Plant Physiol 1992; 19:287-296. http://dx.doi.org/10.1071/PP9920287

11. Reeve WG, Brau L, Castelli J, Garau G, Sohlenkamp C, Geiger O, Dilworth MJ, Glenn AR, Howieson JG, Tiwari RP. The Sinorhizobium medicae WSM419 IpiA gene is transcriptionally activated by FsrR and required to enhance survival in lethal acid conditions. Microbiology 2006; 152:3049-3059. PubMed http://dx.doi.org/10.1099/mic.0.28764-0

12. Reeve $\mathrm{W}$, Chain $\mathrm{P}, \mathrm{O}^{\prime}$ Hara G, Ardley J, Nandesena K, Brau L, Tiwari R, Malfatti S, Kiss H, Lapidus A, et al. Complete genome sequence of the Medicago microsymbiont Ensifer (Sinorhizobium) medicae strain WSM419. Stand Genomic Sci 2010 ; 2:77-86. PubMed http://dx.doi.org/10.4056/sigs.43526

13. Brockwell J, Hely FW. Symbiotic characteristics of Rhizobium meliloti: an appraisal of the systematic treatment of nodulation and nitrogen fixation interactions between hosts and rhizobia of diverse origins. Australian Journal of Agricultural Economics 1966; 17:885-889.

14. Howieson JG, Nutt B, Evans P. Estimation of hoststrain compatibility for symbiotic $\mathrm{N}$-fixation between Rhizobium meliloti, several annual species of Medicago and Medicago sativa. Plant Soil 2000; 219:49-55. http://dx.doi.org/10.1023/A:1004795617375

15. Interrante $S M$, Sing $R$, Islam MA, Stein JD, Young CA, Butler TJ. Effectiveness of Sinorhizobium inoculants on annual medics. Crop Sci 2011; 51:2249-2255. http://dx.doi.org/10.2135/cropsci2011.02.0076 
16. Terpolilli JJ, O'Hara GW, Tiwari RP, Dilworth MJ, Howieson JG. The model legume Medicago truncatula A17 is poorly matched for $\mathrm{N}_{2}$ fixation with the sequenced microsymbiont Sinorhizobium meliloti 1021. New Phytol 2008; 179:62-66. PubMed http://dx.doi.org/10.1111/j.14698137.2008.02464.x

17. Bonython AL, Ballard RA, Charman N, Nichols $\mathrm{PGH}$, Craig AD. New strains of rhizobia that nodulate reg enerating messina (Melilotus siculus) plants in saline soils. Crop Pasture Sci 2011; 62:42 7-436. http://dx.doi.org/10.1071/CP10402

18. Bering er JE. R factor transfer in Rhizobium leguminosarum. J Gen Microbiol 1974; 84:188198. PubMed http://dx.doi.org/10.1099/00221287-84-1-188

19. Howieson JG, Ewing MA, D'antuono MF. Selection for acid tolerance in Rhizobium meliloti. Plant Soil 1988; 105:179-188. http://dx.doi.org/10.1007/BF02376781

20. Field D, Garrity G, Gray T, Morrison N, Seleng ut J, Sterk P, Tatusova T, Thomson N, Allen M, Angiuoli SV, et al. Towards a richer description of our complete collection of genomes and metagenomes "Minimum Information about a Genome Sequence " (MIGS) specification. Nat Biotechnol 2008; 26:541-547. PubMed http://dx.doi.org/10.1038/nbt1360

21. Woese CR, Kandler O, Wheelis ML. Towards a natural system of organisms: proposal for the domains Archaea, Bacteria, and Eucarya. Proc Natl Acad Sci USA 1990; 87:4576-4579. PubMed http://dx.doi.org/10.1073/pnas.87.12.4576

22. Garrity GM, Bell JA, Lilburn T. Phylum XIV. Proteobacteria phyl. nov. In: Garrity GM, Brenner DJ, Krieg NR, Staley JT (eds), Bergey's Manual of Systematic Bacteriology, Second Edition, Volume 2, Part B, Springer, New York, 2005, p. 1.

23. Garrity GM, Bell JA, Lilburn TG. Class I. Alphaproteobacteria In: Garrity GM, Brenner DJ, Krieg NR, Staley JT, editors. Bergey's Manual of Systematic Bacteriology. Second ed. Volume 2: New York: Springer - Verlag; 2005, p. 1.

24. Validation List No. 107. List of new names and new combinations previously effectively, but not validly, published. Int I Syst Evol Microbiol 2006; 56:1-6. PubMed http://dx.doi.org/10.1099/ijs.0.64188-0

25. Kuykendall LD. Order VI. Rhizobiales ord. nov. In: Garrity GM, Brenner DJ, Kreig NR, Staley JT, editors. Berg ey's Manual of Systematic Bacteriol- ogy. Second ed: New York: Springer - Verlag; 2005. p 324.

26. Skerman VBD, McGowan V, Sneath PHA. Approved Lists of Bacterial Names. Int / Syst

Bacteriol 1980; 30:225-420. http://dx.doi.org/10.1099/00207713-30-1-225

27. Conn HJ. Taxonomic relationships of certain nonsporeforming rods in soil. J Bacterio/ 1938; 36:320-321.

28. Judicial Commission of the International Committee on Systematics of $\mathrm{P}$. The genus name Sinorhizobium Chen et al. 1988 is a later synonym of Ensifer Casida 1982 and is not conserved over the latter genus name, and the species name 'Sinorhizobium adhaerens' is not validly published. Opinion 84. International Journal of Systematic and Evolutionary Microbiology 2008;58(Pt 8):1973.

29. Young JM. The genus name Ensifer Casida 1982 takes priority over Sinorhiz obium Chen et al. 1988, and Sinorhizobium morelense Wang et al. 2002 is a later synonym of Ensifer adhaerens Casida 1982. Is the combination "Sinorhizobium adhaerens" (Casida 1982) Willems et al. 2003 legitimate? Request for an Opinion. Int J Syst Evol Microbiol 2003; 53:2107-2110. PubMed http://dx.doi.org/10.1099/ijs.0.02665-0

30. Casida LE. Ensifer adhaerens gen. nov., sp. nov.: a bacterial predator of bacteria in soil. Int J Syst Bacteriol 1982; 32:339-345. http://dx.doi.org/10.1099/00207713-32-3-339

31. Agents B. Technical rules for biological agents. TRBA (http://www.baua.de):466.

32. Liolios K, Mavromatis K, Tavernarakis N, Kyrpides NC. The Genomes On Line Database (GOLD) in 2007: status of genomic and metag enomic projects and their associated metadata. Nucleic Acids Res 2008; 36:D475-D479. PubMed http://dx.doi.org/10.1093/nar/g km884

33. Tamura K, Peterson D, Peterson N, Stecher G, Nei M, Kumar S. MEGA5: Molecular Evolutionary Genetics Analysis using Maximum Likelihood, Evolutionary Distance, and Maximum Parsimony Methods. Mol Biol Evol 2011; 28:2731-2739. PubMed http://dx.doi.org/10.1093/molbev/msr121

34. Nei M, Kumar S. Molecular Evolution and Phylog enetics. New York: Oxford University Press; 2000. 
35. Felsenstein J. Confidence limits on phylog enies: an approach using the bootstrap. Evolution 1985; 39:783-791. http://dx.doi.org/10.2307/2408678

36. Galibert F, Finan TM, Long SR, Puhler A, Abola P, Ampe F, Barloy-Hubler F, Barnett MJ, Becker A, Boistard $\mathrm{P}$, et al. The composite genome of the leg ume symbiont Sinorhizobium meliloti. Science 2001; 293:668-672. PubMed http://dx.doi.org/10.1126/science.1060966

37. Ashburner M, Ball CA, Blake JA, Botstein D, Butler H, Cherry JM, Davis AP, Dolinski K, Dwight SS, Eppig JT, et al. Gene ontology: tool for the unification of biology. The Gene Ontology Consortium. Nat Genet 2000; 25:25-29. PubMed http://dx.doi.org/10.1038/75556

38. Ballard RA, Slattery JF, Charman N. Host range and saprophytic competence of Sinorhizobium melilot $i$ - a comparison of strains for the inoculation of lucerne, strand and disc medics. Aust J Exp Agric 2005; 45:209-216. http://dx.doi.org/10.1071/EA03126

39. Reeve WG, Tiwari RP, Worsley PS, Dilworth MJ, Glenn AR, Howieson JG. Constructs for insertional mutagenesis, transcriptional signal localization and gene regulation studies in root nodule and other bacteria. Microbiology 1999; 145:1307-1316. PubMed http://dx.doi.org/10.1099/13500872-145-6-1307

40. DOE Joint Genome Institute. http://my.jgi.doe.gov/general/index.html

41. Bennett S. Solexa Ltd. Pharmacogenomics 2004; 5:433-438. PubMed http://dx.doi.org/10.1517/14622416.5.4.433

42. Zerbino DR. Using the Velvet de novo assembler for short-read sequencing technologies. Current Protocols in Bioinformatics 2010; Chapter 11:Unit 115.

43. Ewing B, Green P. Base-calling of automated sequencer traces using phred. II. Error probabilities. Genome Res 1998; 8:175-185. PubMed http://dx.doi.org/10.1101/gr.8.3.175

44. Ewing B, Hillier L, Wendl MC, Green P. Basecalling of automated sequencer traces using phred. I. Accuracy assessment. Genome Res 1998; 8:175-185. $\underline{\text { PubMed }}$ http://dx.doi.org/10.1101/gr.8.3.175
45. Gordon D, Abajian C, Green P. Consed: a graphical tool for sequence finishing. Genome Res 1998; 8:195-202. PubMed http://dx.doi.org/10.1101/g r.8.3.195

46. Hyatt D, Chen GL, Locascio PF, Land ML, Larimer FW, Hauser LJ. Prodigal: prokaryotic gene recognition and translation initiation site identification. BMC Bioinformatics 2010; 11:119. PubMed http://dx.doi.org/10.1186/1471-2105-11-119

47. Pati A, Ivanova NN, Mikhailova N, Ovchinnikova G, Hooper SD, Lykidis A, Kyrpides NC.

GenePRIMP: a gene prediction improvement pipeline for prokaryotic genomes. Nat Methods 2010; 7:455-457. PubMed http://dx.doi.org/10.1038/nmeth. 1457

48. Lowe TM, Eddy SR. tRNAscan-SE: a prog ram for improved detection of transfer RNA genes in genomic sequence. Nucleic Acids Res 1997; 25:955-964. PubMed

49. Lagesen K, Hallin P, Rodland EA, Staerfeldt HH, Rognes T, Ussery DW. RNAmmer: consistent and rapid annotation of ribosomal RNA genes. Nucleic Acids Res 2007; 35:3100-3108. PubMed http://dx.doi.org/10.1093/nar/g km160

50. Griffiths-Jones S, Bateman A, Marshall M, Khanna A, Eddy SR. Rfam: an RNA family database. Nucleic Acids Res 2003; 31:439-441. PubMed http://dx.doi.org/10.1093/nar/g kg 006

51. Krogh A, Larsson B, von Heijne G, Sonnhammer EL. Predicting transmembrane protein topology with a hidden Markov model: application to complete genomes. J Mol Biol 2001; 305:567580. PubMed http://dx.doi.org/10.1006/jmbi.2000.4315

52. Bendtsen JD, Nielsen H, von Heijne G, Brunak S. Improved prediction of signal peptides: SignalP 3. 0. J Mol Biol 2004; 340:783-795. PubMed http://dx.doi.org/10.1016/j.jmb.2004.05.028

53. Markowitz VM, Mavromatis K, Ivanova NN, Chen IM, Chu K, Kyrpides NC. IMG ER: a system for microbial genome annotation expert review and curation. Bioinformatics 2009; 25:2271-22 78.

$\underline{\text { PubMed }}$ http://dx.doi.org/10.1093/bioinformatics/btp393 